\title{
To BIM or not to BIM: A pilot study on University of Malaya's architectural students' software preference
}

\author{
Mohd Farizuda Rosli, Asrul Sani Razak, Mohammed AmerYounus \\ Department of Architecture, Faculty of Built Environment, University of Malaya, Kuala Lumpur, \\ Malaysia \\ *farizuda@um.edu.my
}

In recent years, Building Information Modelling (BIM) has received enormous attention from the Architectural, Engineering and Construction (AEC) industry around the globe. In 2014, the first Malaysia's international BIM day was held at Putra World Trade Centre (PWTC) Kuala Lumpur that marked the largest awareness event to highlight the nationwide BIM adoption and implementationpromotion campaign on this new technology. To ensure the success in the implementation, it isimportant for future architectural graduates to be equipped with the operational skill of thesoftware.This, in turn, requires architecture schools in Malaysia to consider adjusting theircurriculums, and syllabus in preparing their students for the demand of the AEC industry. Thisstudy aims to explore and understand the architectural students' perception towards theadvantage of using BIM software in their design studio projects. An exploratory study has been conducted through a survey among 84 respondents in 3rd, 4th and 5th year of the architectureprogram at the University of Malaya (UM). The result indicates that both AutoCAD and SketchUp are the most commonly used software in both education and practice. In contrast, BIM softwareis found to be less commonly used by the students. This BIMsoftware however does receive positive feedback from the students for its benefits. This could indicate a prospect to embrace BIM technology into UM's architectural syllabus.

Keywords: Architectural Education, BIM, 3D software, Design Studio

\subsection{INTRODUCTION}

As the progress of computer starts to kick-in in the early 1980's, architects begin to use ComputerAided Design (CAD) to automate their orthographic drawings which before was expressed manually using $\mathrm{T}$-squares and pencils (Levy, 2012). As the complexity of building forms, structure, and services continue to rise, a new set of technology has to be made available to cater for the more sophisticated practice of design and construction.

Building Information Modelling (BIM) extends from other past drafting tools by using the 3D model as an interactive database that contains all the required information of a building design proposal(Waterhouse, 2013). According to Kivits \& Furneaux, (2013), BIM has the momentum for sustainability to be practiced in all stages from planning and design stage, construction, to facilities management stage of a building. BIM is a useful tool that could further add value on the architectural design proposal by enabling a building to be modelled and simulated in order to achieve optimumenergy and cost effectiveness.
Such process has even facilitated the architects and other construction industry players to ensure that the proposed building is in accordance to the sustainability agenda.

In the report entitled 'The Direction of Architectural Education in Malaysia', the Ministry of Higher Education of Malaysia (MOHE) stressed upon the aim and aspiration of the higher public education in Malaysia that is to ensure the architecture programme in Malaysia is able to compete internationally in the aspect of knowledge generation as well as the employability of their graduates (Kementerian Pengajian Tinggi Malaysia, 2011). BIM, in this context, is considered as emerging digital tool utilised in many parts of the AEC industries in developing and developed countries (Azhar, et. Al, 2008; CIDB Malaysia, 2014; NATSPEC Australia, 2014; RIBA Enterprises Ltd, 2015). In recent survey study by Auburn University with industry participants in the USA, $75 \%$ of the industry players regarded BIM as an advantage to their employment candidates over those with lack or without BIM knowledge (Azharet. Al, 2008). Similarly, in RIBA Appointments Skills Survey 
2014, BIM is considered as one of the most desirable experience and skills sought by the architectural firms in the UK (RIBA Enterprises Ltd, 2015).

In Malaysian context, various workshops, seminars and conferences spearheaded by Construction Industry Development Board of Malaysia (CIDB) since 2013 was probably one of the government'sefforts to promote BIM technology to the AEC. However, the construction industry is by large, still in shortage of competent and reliable BIM modellers - AEC professional with the technical know-how of BIM software (CREAM, 2014). Therefore, it is important for future generation of architects to acquire the knowledge of this technology in their early educational years.

\subsection{THE STUDYAIM AND OBJECTIVES}

This study aims is to investigate the use and perception of digital tools and technologies among the architecture students in higher learning institutions in Malaysia. Therefore, this study acts as a pilot study to explore the potential of BIM software implementation in architectural design curriculum.

First, this study investigates the students' software usage - including any BIM software through their prior training, experience and education. The usage of BIM relies heavily on the usage of appropriate BIM software for it to work. Hence, identifying softwares that they use would indicate whether or not there is already an adoption of BIM.

Second, the study investigates the students' perception with regard to BIM and non-BIM software. Two 3D architectural design softwares, namely Autodesk Revit (BIM software) and SketchUp (non-BIM software) are specifically mentioned in the survey questionnaires. Although there are many software available in the market, the two 3D software are selected in this survey due to the fact that SketchUp is the most used 3D modelling software whereas Revit is the most used BIM software in Malaysia (Mohd-Nor \& Grant, 2014; Eastman et. al., 2011).

\subsection{BUILDING INFORMATION MODELLING (BIM)}

While there are many definition on the term Building Information Modelling (BIM), in Malaysia's context, according to the Steering Committee of Building Information Modelling Malaysia, from their first meeting on the 24th July
2013, the committee defined BIM as 'modelling technology and associated set of processes to produce, communicate and analyze digital information models for construction life-cycle' (CIDB Malaysia, 2014). In short, BIM is a work practice within a given set of new technology. While BIM is a term that has been a while in engineering and manufacturing industries, it is now starting to create an impact in Malaysia's building industry.

Technically speaking, the implementation processes of BIM moves away from using conventional Computer Aided Drafting (CAD) into the use of common standards and object orientated representations. This is accomplished by making a single and centralised 3D digital model as a primary tool for production of a more increasing documentation requirement, such as schedules, plans and bills of quantities (Pittard, 2012). Thus, aBIM model consists of digital representations of the actual parts and pieces used to construct a building together with accurate measure of spatial relationships, geometry, cost and quantity take off, analytical information and properties of building components. With BIM, the entire building lifecycle from construction through to the demolition are possible to be simulated (Renaud Vanlande, 2008). Because of its significant benefits, many governments worldwide are currently pushing BIM into their building construction industry, including Malaysia.

\subsection{THE APPLICATION OF BIM IN MALAYSIA}

In Malaysia, although BIM software was only available since the year 2002, its momentum of BIM only started to grow by 2010 (Ahmad Tarmizi et al., 2012). Since then, there were many efforts driven on the awareness program and the government initiated their first project using BIM in 2010 with the construction of the National Cancer Institute project (Ahmad Tarmizi et al., 2012; CREAM, 2014). The first Malaysia's International BIM day was held on $22^{\text {nd }}$ September 2014 at Putra World Trade Centre (PWTC) Kuala Lumpur that marks the largest awareness event to highlight the national BIM adoption and implementation promotion campaign on this new technology.

However, BIM in Malaysia at large is still in the pre-BIM stage, where the focus is to instil awareness of the technology to the industry players and to develop the competency of 3D Object-Based-Modelling (3D OBM) as a better alternative to 2D Line-Based-Draughting (2D 
LBD) that is commonly used in the conventional CAD system. According to the BIM Performance Measurement developed by Succar (2009), this stage is called the BIM stage 1 - the stage where the industry players are developing their ways to migrate from 2D LBD into 3D OBM.

Construction Research Institute of Malaysia, (2014) stated that the government of Malaysia perceived BIM as an important tool to manage built properties, hence the government is targeting for the implementation of BIM by the year 2016(CREAM, 2014). Thus, in order to push forward the development of BIM in Malaysia, it is necessary for the AEC industry to be well equipped with personnel with appropriate skills and technical competencies of BIM tools.

\subsection{INTRODUCTION TO BIM IN THE DEPARTMENT OF ARCHITECTURE AT UNIVERSITY OF MALAYA}

As there are no available records with regard to BIM education in Malaysia, the focus then specifically targeted at BIM educational development in the University of Malaya (UM). The architecture program at UM was established in 1995 as a small unit in the Faculty of Engineering. In 2001, a new faculty by the name of the Faculty of Built Environment was established, comprises of four departments; Department of Architecture, Department of Building Surveying, Department of Quantity Surveying and Department of Estate Management. In 2012, the Faculty of Built Environment introduced another department called the Department of Urban Planning and a year later, the whole Faculty moved to a new building with state of the art tools and technologies to support the teaching and learning of these diversified courses. In undergraduate architecture, the teaching of CAD was mainly taught during the second year level. The CAD course has two parts; the first part is mainly for $2 \mathrm{D}$ drafting and the second part is mainly for 3D modelling and animation.

In 2007, a number of lecturers from the department of architecture established a focus group with several architectural students to initiate a pilot study to compare the BIM software with other architectural drawing production, namely ArchiCAD and Revit. At this time, there was not any specific or dedicated course or teaching subject pertaining BIM. In 2011, the study was continued with the formation of training courses conducted on BIM software, namely Autodesk
Revit Architecture to $3^{\text {rd }}$ year architecture students (graduating Part 1 students). The course was not part of the curriculum syllabus of the department, but ratheras Part of the government's initiative leading from the Ministry of Higher Education's (MoHE) program called 3P Industry-based Certification Program (Program Pentauliahan Professional).

The government's initiative program provided Industry-Based Certification Program for final year students of selected Faculties from UM, and it was also offered to faculty staff such as lecturers and technical staff. At the end of the training, the participants would sit for an examination that would enable them to receive an Autodesk certification of competency with regard to a particular software training that they had completed. However, after the government's initiative, the faculty did not have any further training on BIM or the BIM software.

\subsection{LIST OF BIM SOFTWARE}

BIM softwares or platforms can be used for different function in building construction. It can be used for design modelling and drawing production, for structural or building performance data management, for developing a construction coordination modelling or scheduling, for fabrication detailing or for facility management according to the most common BIM software used in the market and industry listed in Table 1.0 (2011). For the purpose of this paper, Revit software is elaborated in one section to give a general understanding of the capability of the software as this study compares this particular BIM software - Revit, to a non-BIM 3D software that is been widely used in Malaysia's architectural companies - SketchUp(Mohd-Nor \& Grant, 2014).

\subsection{AUTODESK REVIT}

Revit was developed by two individuals that came from the company called Parametric Technology Corporation (PTC), Irwin Jungreis and Leonid Raiz(AUGI - Autodesk User Group International, 2013). Both of them wanted to create an architectural version of Pro/ENGINEER software which was created as a mechanical CAD program by PTC. They split from PTC and started their own software company on October $31^{\text {st }}, 1997$ called Charles River Software in Cambridge, Massachusetts (Bergin, 2012). 
Table 1.0: Most common architectural BIM software available in the market. (Eastman et. al. ,2011)

\begin{tabular}{|c|c|}
\hline Software & Developer \\
\hline ArchiCAD & Graphisoft \\
\hline Bentley Architecture & Bentley Systems \\
\hline Revit & Autodesk \\
\hline Vectorworks & Graphisoft \\
\hline Digital Project & Gehry Technologies \\
\hline
\end{tabular}

By the year 2000, the company developed software called 'Revit' which came from the combination of the two words 'Revise Instantly' (AUGI - Autodesk User Group International, 2009; Taylor, 2009). Revit was written in C++ programming and was programmed as an object based software that utilizes parametric change to the created digital object. Revit was developed specifically with architecture in mind and was purposely built by architects for architects as the majority of Revit's product development teams are architects or came from a design and construction background (AUGI - Autodesk User Group International, 2013).

In general, Revit provides an easy to use interface with its smart cursor and drag-over tips for each operation. Its drawing generation is based on associative and offers bidirectional editing, from drawings to the model, or the schedules or vice versa, and Revit supports the creation of a new custom parametric objects. Revit creates a revolution in the world of BIM by creating a visual environment for the creation of parametric objects and enabling time dimension - the fourth dimension; to be associated with the building objects. This fourth dimension feature enables contractors to simulate the construction process and generate construction schedules.

In 2002, Autodesk company purchased Charles River Software company, which at that time had be known as Revit Technology Corporation, for $\$ 133$ million and began to heavily promote the Revit software (Bergin, 2012; AUGI - Autodesk User Group International, 2013). Since then, Revit has become the most used BIM software throughout the world (Kiker, 2009; Eastman et. al., 2011; Teer, 2014; MohdNor \& Grant., 2014).

\subsection{SKETCHUP}

SketchUp is a 3D modelling software for architectural design, civil, and other 3D design purposes. SketchUp is a convenient tool to generate quick and initiative 3D models with its push/pull-patented technology (Mohd-Nor \& Grant, 2014) and it also has an online free model library repository - Google 3D Warehouse - for anyone to learn, copy and modify these 3D models. The software includes drawing layout, and it also supports third-party "plug-in" as extensions to enhance the capability of the software such as rendering and various aspects of modelling techniques. SketchUp provides users with ease of use, flexibility, accuracy, and versatility in both $2 \mathrm{D}$ and $3 \mathrm{D}$ modelling environment. In addition, SketchUp also can classify geometry and assign schema tags to groups and components of digital models.

SketchUp is an excellent application for rapid development of a schematic design phase of a building proposal, however, unlike BIMsoftware; it has limited use for any other type of analysis because of the absence of informational properties of digital objects except for their appearance for visualization and its geometry (Eastman et. al., 2011).

\subsection{METHODOLOGY}

The primary data of this study comes from a pilot survey study where a questionnaire survey was distributed to Part 1 and Part 2 architecture students at the University of Malaya, Kuala Lumpur. A total of 44 students responded to the questionnaire.

The questionnaire is divided into three sections. The first section covers the respondents' profile including the respondent's year of study, working experience and their most used software during their work. The second section covers the students' software usage for their design studio project with any former training or prior training or classes with regard to the software studied. The last section of the questionnaire covers the perception of students' on BIM and non-BIM software.

\subsection{POPULATION AND SAMPLING SIZE}

A total of 84 surveys were distributed to 55 students from 3rd year (Part 1), 11 students from 4th year (Part 2) and 18 students from 5th year (Part 2). Out of the 55 students from the 3rd year, a valid responds of 30 respondents were received 
which equals to 54.5\% responds rate from the targeted Part 1 students. From the Part 2, out of the 11 students, only 6 valid responds were received from 4th year and 8 valid responds out of the total 18 from 5th year students, which in total equals to $48.3 \%$ of responds rate from Part 2 students. The summary of the total population, sampling size and the response rate for this study are shown in Table 2.0 and Figure 1.0.

It must be noted that the survey only focuses on students from the three year of undergraduate study as only these students have the experience of using 3D modellingsoftwares for at least one year as the 3D design software courses in UM are taught in their 2nd year of study. Majority of the students also had some work experience or at least had gone out for their practical training. This set of students would have experience working with particular architectural design software in their study as well as in real work practice.

Table 2.0: Population, sampling size and response rate for the study

\begin{tabular}{|c|c|c|c|c|}
\hline $\begin{array}{c}\text { Part 1 / Part } \\
\mathbf{2}\end{array}$ & $\begin{array}{c}\text { Year of } \\
\text { Study }\end{array}$ & $\begin{array}{c}\text { Population } \\
\text { (Person) }\end{array}$ & $\begin{array}{c}\text { Valid Response received } \\
\text { (Nos) }\end{array}$ & $\begin{array}{c}\text { Responds Rate } \\
\text { (\%) }\end{array}$ \\
\hline \multirow{2}{*}{ Part 1 } & 3rd Year & 55 & 30 & 54.5 \\
\hline \multirow{2}{*}{ Part 2 } & 4th Year & 11 & 6 & \multirow{2}{*}{48.3} \\
\cline { 2 - 4 } & 5th Year & 18 & 8 & \\
\hline
\end{tabular}

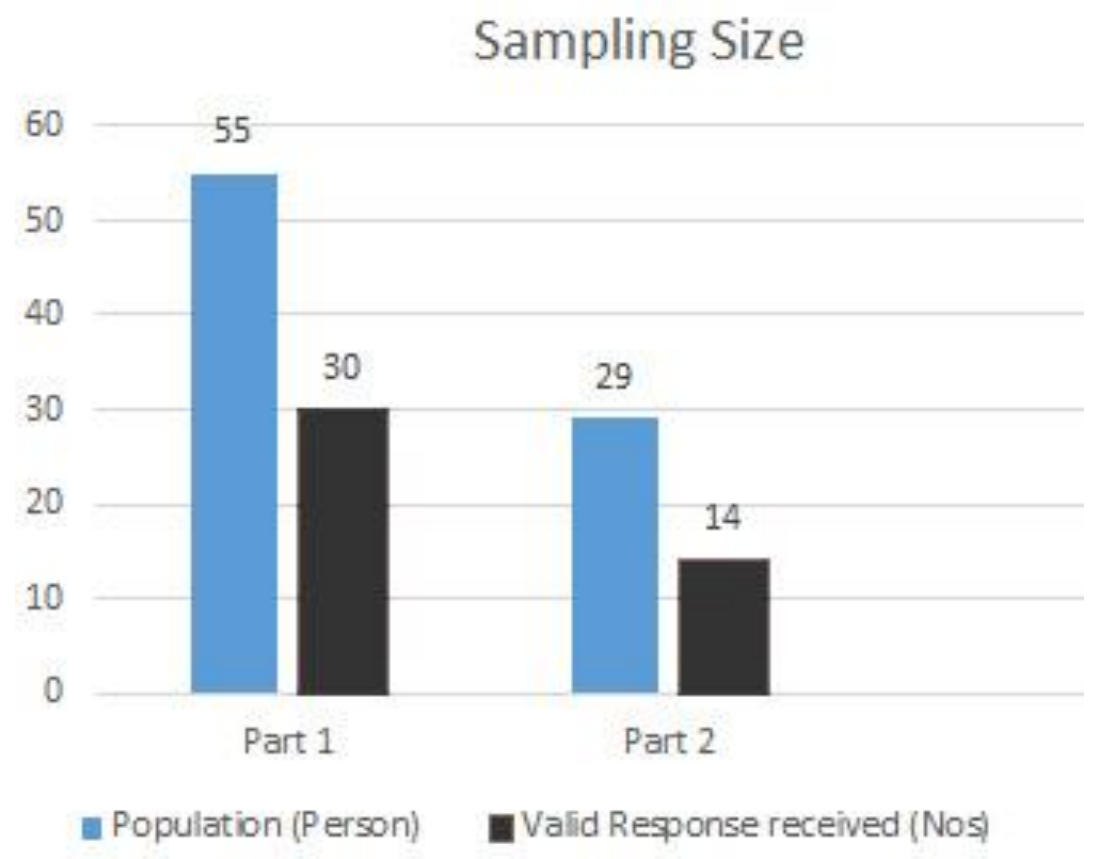

Figure 1.0: Sampling size in relation to the population of study

The 3rd year and 5th year survey data provides valuable input for this study as they are in their graduating years of their study. Their preferences data on the software could be used for further study either on the students' readiness to the industry with the appropriate software knowledge or a study that looks into the industry's demand on students' skills and knowledge.

\subsection{FINDINGS AND DISCUSSION}

A descriptive statistical analysis was conducted to explain the results of this study.The analysis was derived into findings from Part 1 and Part 2 level of architecture students separately. This separation of analysis was to compare the results of the two groups of students. The Part 1 architecture students will be graduating after three year 
architectural education to become assistant architect or a technical assistant to a building design project while Part 2 students will be graduating as a graduate architect. These two groups eventually will have a different set of role and speciality in a building design projects. Most of the Part 2 students have had a proper work experience prior to their current study while the Part 1 students in this study have had only a brief period of practical training. The depth of knowledge that the two groups would have on the questions for this study should be different.

The primary data collected from the questionnaire went through two levels of analysis. The first level looks into the students' knowledge about the design software. This includes data on the student's work experience, prior training on the software as well as the usage of the design software. The second level analysis focuses on the students' understanding of using BIM and nonBIM software. In the questionnaire, the students were given Autodesk Revit as the BIM software and SketchUp as the non-BIM software for them to assess accordingly. The secondary data for this study comes mainly from books and selections of peer-reviewed materials such as journal articles and conference paper.

\subsection{RESPONDENTS' PROFILE}

Based on the received data, a total of 30 students from Part 1 (3rd Year) and 14 students from Part 2 ( 4 th year $=6$; 5 th year $=8$ ) participated in this study. Only $30 \%$ of the respondents from Part 1 had some work experience in an architectural company with a time period ranging from two months to one year. On the other hand, all respondents (100\%) from Part 2 have had former work experience in architectural companies with a time period ranging from one month to two years.

The students were then asked about the design software that most frequently being used during their working time in their respective company. From the survey, it was found that all Part 1 students used AutoCAD (100\%). A majority of them have also used SketchUp (88.9\%) during their work. Revit and 3DStudioMax were the least commonly used software within the working office for the Part 1 students as shown in Figure 2.0. Other software that has also been identified by the respondents to be complementary software was Adobe Photoshop and Adobe Illustrator.

Nearly similar result to their Part 1counterparts, for Part 2 students, AutoCAD was shown to be the most commonly used software throughout their previous working period with their respective architectural companies (77.8\%). It was followed by SketchUp with $66.7 \%$. A few numbers of respondents (27.8\%) from Part 2 have had experience using Revit software during their work with their respective company. Vector Works and 3DStudioMax were the least common software that was used by Part 2 respondents during their work, both with similar percentage of $11.1 \%$ as shown in Figure 3.0.

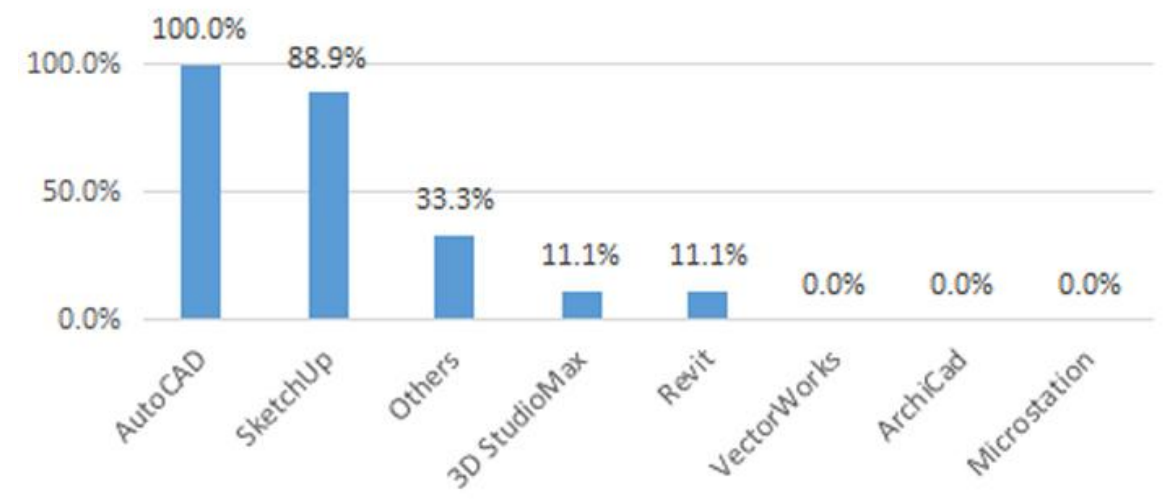

Figure1.0: Percentage of mostly used software by Part 1 students from their work experience. 


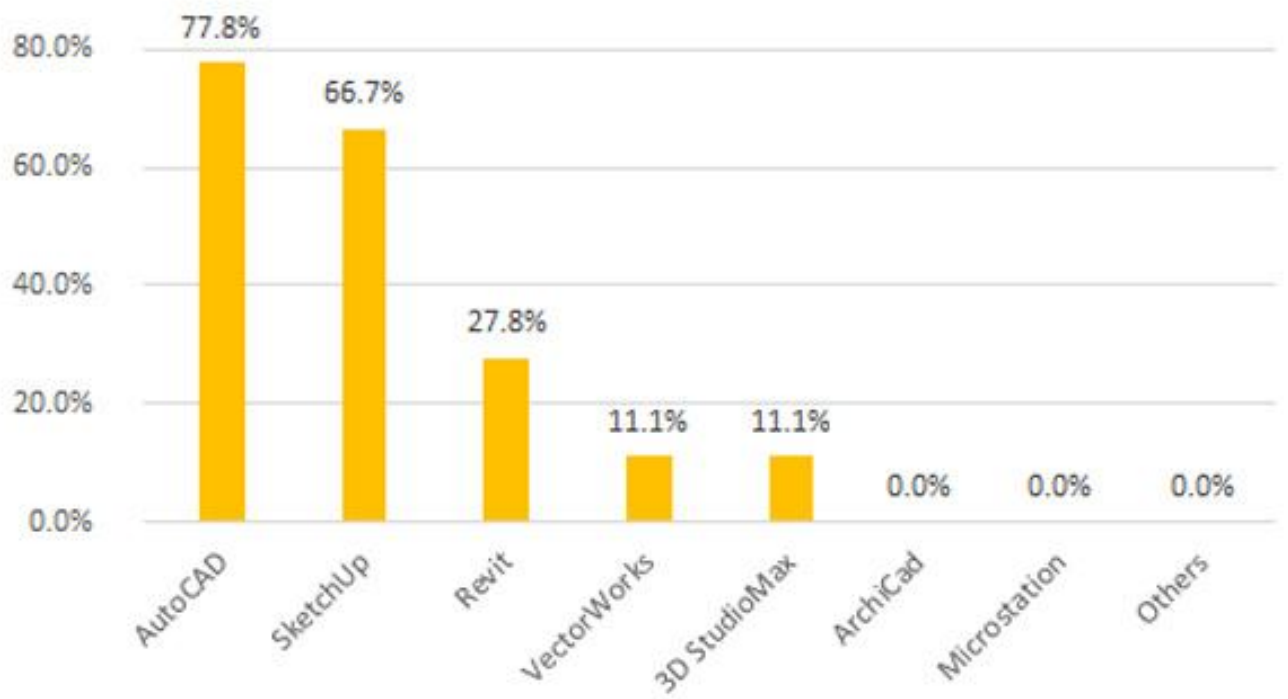

Figure 3.0: Percentage of mostly used software by Part 2 students from their work experience.

Based on the above figures, AutoCAD is found to be the most commonly used software in architectural practice. According to BurcuŞenyapılı and BurcuGökçenBozdağ (2012), the main reason why architecture professionals keen to use AutoCAD is due to its 'flexibility and sufficiency in 2D drawing' as well as '2D graphical presentation ability'. In addition, the architecture professionals have became more familiar with AutoCAD interface and its properties for almost three decades in the market in Malaysia (Mohd-Nor, Usman, \& Mazlan-Tahir, 2009).

\subsection{STUDENTS' SOFTWARE PREFERENCES}

This second section discusses about the students' most commonly used software for their architectural design studio project.

Based on the survey result, AutoCAD and SketchUp were the most commonly used software by the Part 1 students with percentage of $96.7 \%$ and $93.3 \%$ respectively (Figure 4.0 ). Similarly, for Part 2 students, AutoCAD and SketchUp were ranked as the most commonly used software for their design studio project with a slightly lower percentage than their Part 1 counterparts with a percentage of $72 \%$ for both softwares (Figure 5.0 ).
This result of AutoCAD and SketchUp as the most used software by the students in their design studio project matches perfectly with the previous findings (Figure 2.0 and Figure 3.0) and the findings of Mohd-Nor \& Grant (2014) specifically in Malaysia's context. In an article entitled 'The Development of Digital Architecture Modeling in the Malaysian Architecture Industry', Mohd Nor \& Grant (2014) carried out a survey to 140 architecture firms in Malaysia and found out that AutoCAD is the main software being used while SketchUp is the main 3D modelling software being used by the architecture firms in Malaysia.

At the international level however, Revit software has overtaken AutoCAD in the demand for architecture software. Based on a survey from 928 job postings of the top 50 architecture firms all over the world by Teer (2014), over $70 \%$ of architecture jobs require Revit skills, and only over $50 \%$ require AutoCAD skills. The third software skill required by the architecture firms is Sketchup (Teer, 2014). This difference shows that at international level, Revit software is highly in demand as the development of BIM, especially in the developed countries are more advanced compared to Malaysia which has just started to delve into BIM since 2010 (Haron, et al., 2012). 


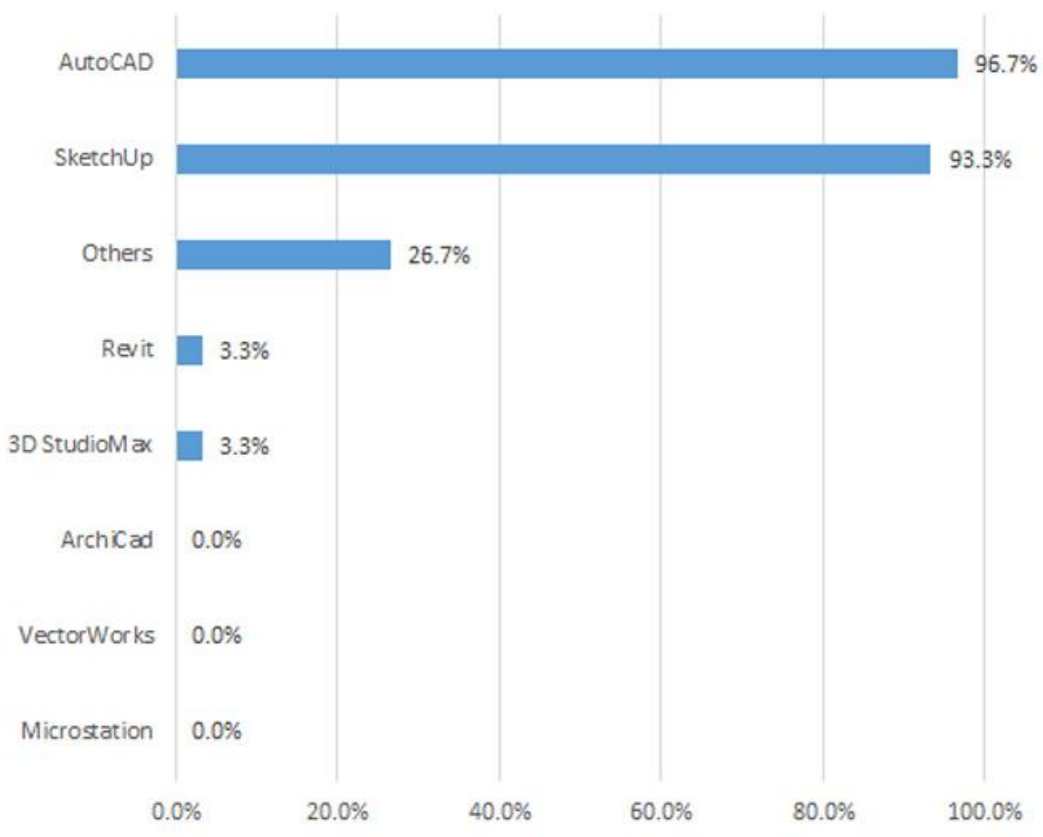

Figure 4.0: Percentage of most used software for design studio project by Part 1 students

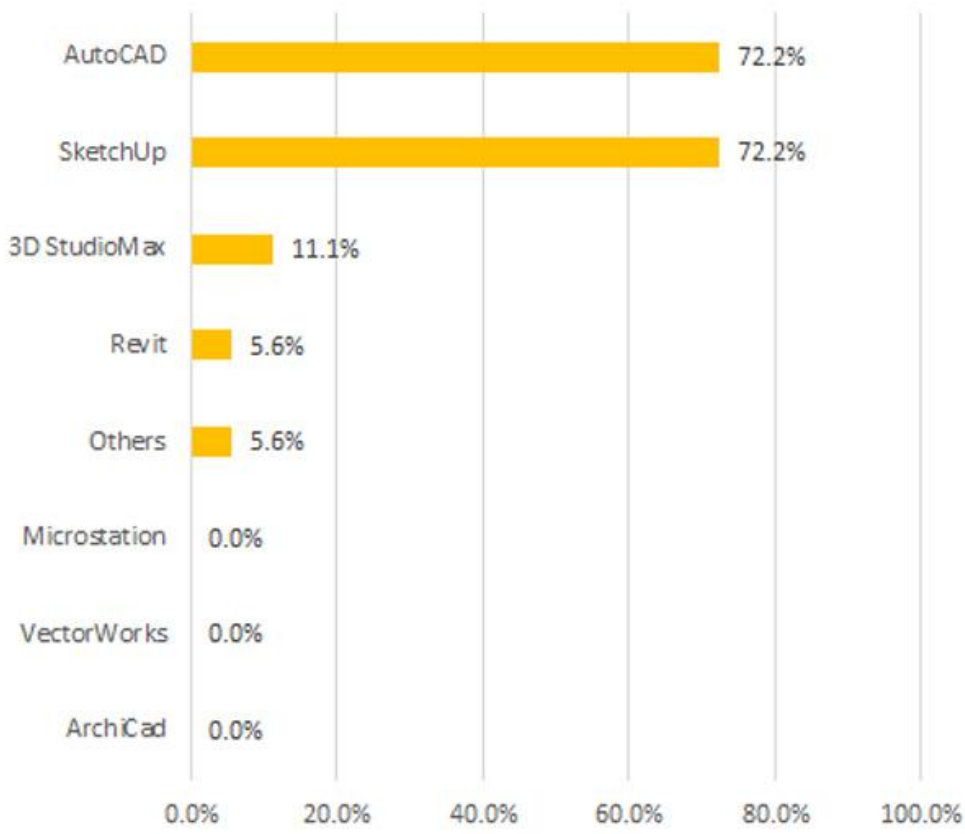

Figure 5.0: Percentage of most used software for design studio project by Part 2 students

\subsection{STUDENTS' PERCEPTION ON BIM/NON-BIM SOFTWARE}

In this section of the survey, a series of questions were asked in the survey to gauge the students' perception between one BIM software - Autodesk Revit, and one non-BIM software - SketchUp. The survey questions were given in a likert scale format; with 5 range of scale ranging from strongly disagree to strongly agree for each given statement. The result of the survey is tabled out in a chart that indicates the number of count for each scale. Each scale was represented in different colours - strongly agree (dark green), agree (light green), neither agree nor disagree (grey), disagree (orange), and strongly disagree (red). The modes for each statement in the chart were highlighted 
with black outline in the chart. The result for Part 1 and Part 2 students are discussed separately.

\subsubsection{Students' perception on Autodesk Revit Software (BIMSoftware)}

As shown in Figure 6.0, the perception survey result of Revit software for Part 1 students can be summarized as follow:

Majority of Part 1 students neither agree nor disagree (grey colour) with the statements on:

- The software's simplicity

- The software's ability to enhance the student's creativity

- The image rendering quality

- Data compatibility between IES-VE (building performance analysis software) and Revit

- Its ability to give constructional information

- $\quad$ The use of the software by the students in the design studio project
- Market demand for this software

However, they do agree (light green colour) on these statements:

- The software could save time

- Is able to ease with the production of $2 \mathrm{D}$ drawings

- Detail drawings production

- Architecture students should have knowledge on this particular software

In general, Part 1 students tend to have a high percentage of uncertainty to this software but with a considerable consensus on the benefits that the software could offer. The result shows that although Part 1 students did not have any particular training or experience using the software before, they still have a positive outlook towards this software.

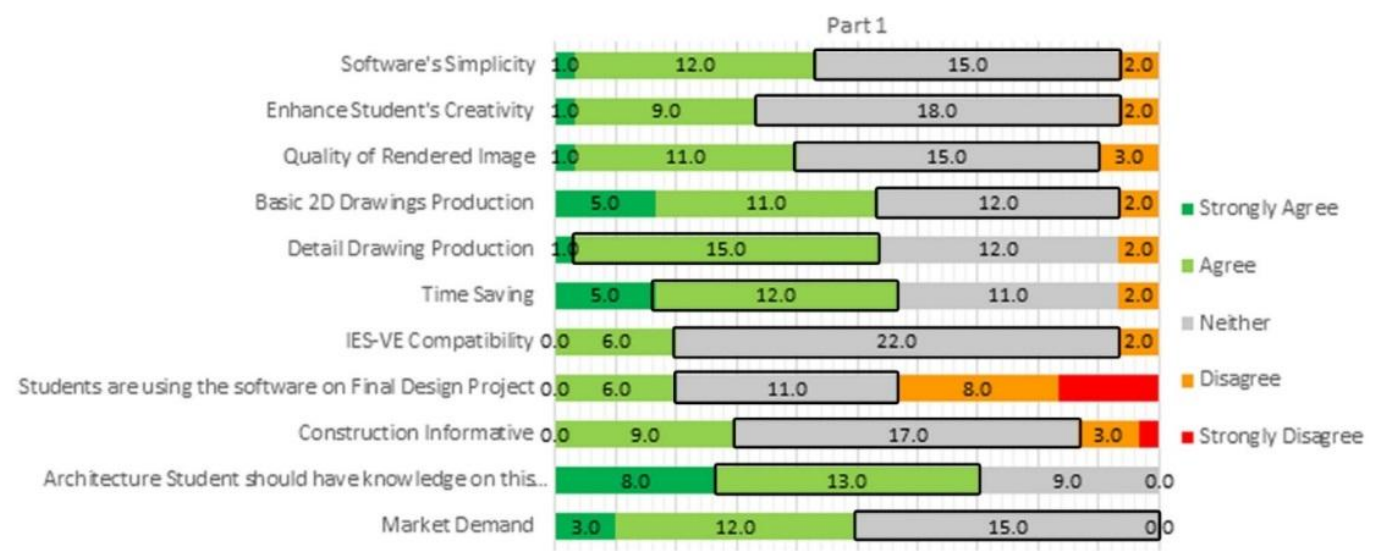

Figure 6.0: Part 1 students' perceptions on Revit software

On the other hand, the perception results of Revit software from the Part 2 students were more diverse in terms of their agreement to the statements regarding the software (Figure 6.1). The perception survey result for Part 2 students can be summarized as follow:

Majority of the Part 2 students agreed (light green colour) on the statements on:

- The software's simplicity

- Is able to ease with the production of 2D drawings

- Detail drawings production

- Its ability to give constructional information
- Architecture students should have knowledge on this particular software

- Market demand for this software (strongly agree)

However, Part 2 students were uncertain (grey colour) on the statements:

- The software's ability to enhance the student's creativity

- $\quad$ The image rendering quality

- Data compatibility between IES-VE (building performance analysis software) and Revit 
The only thing that they disagree (orange colour) on was:

- The use of the software by the students in the design studio project

Part 2 students generally had more knowledge on the benefits and advantages that this BIM software could give to them. Such knowledge that the students had might come from their former work experience or from information gathered from their peers or colleagues who had experience using this software. Similar to the Part 1 students, although Part 2 students did not have any particular training with Revit software, they still have a positive outlook towards this software. Figure 6.2 shows both Part 1 and Part 2 perception on Revit results have been put side by side as a comparison.

\subsubsection{Students' perception on Sketchup Software (non-BIM software)}

From the result of Part 1 students' perception on SketchUp software, generally most of them agreed (light green colour) with almost all of the statements about the software in the survey except for 3 statements that they were unsure of (Figure 7.0).

The students agreed on:

- The software's simplicity

- The software's ability to enhance the student's creativity
- Is able to ease with the production of 2D drawings

- The software could save time

- Its ability to give constructional information

- Architecture students should have knowledge on this particular software

- The use of the software by the students in the design studio project

- Market demand for this software

The students were uncertain (grey colour) on the statements:

- $\quad$ The image rendering quality

- Detail drawings production

- Data compatibility between IES-VE (building performance analysis software) and SketchUp

Mainly, Part 1 students were in favour of the SketchUp software usage as this software is one of the software that was taught as a course in their syllabus. Moreover, the interface of SketchUp with handy toolbar made it a huge time saver for those students who seek speed in their design process. SketchUp only requires a low specification computer to run on. Any normal Personal Computer (PC) or laptop would be able to get the software up and running. These ease and 'friendliness' made the software more favourable to be installed and used by the student.

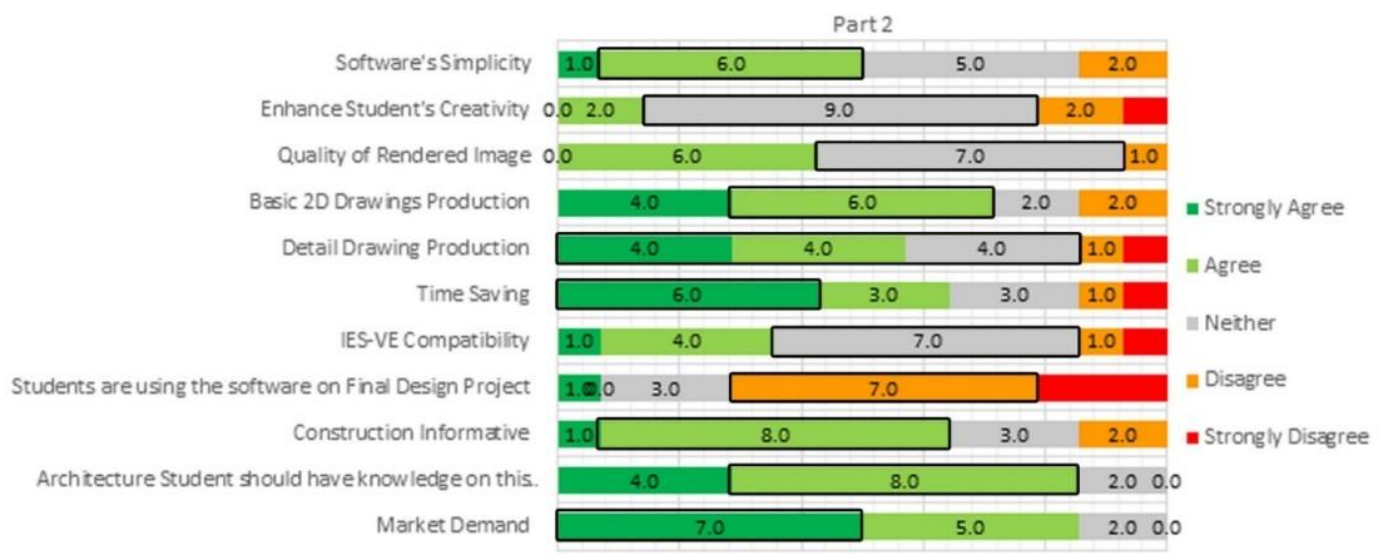

Figure 6.1: Part 2 students' perceptions on Revit software 


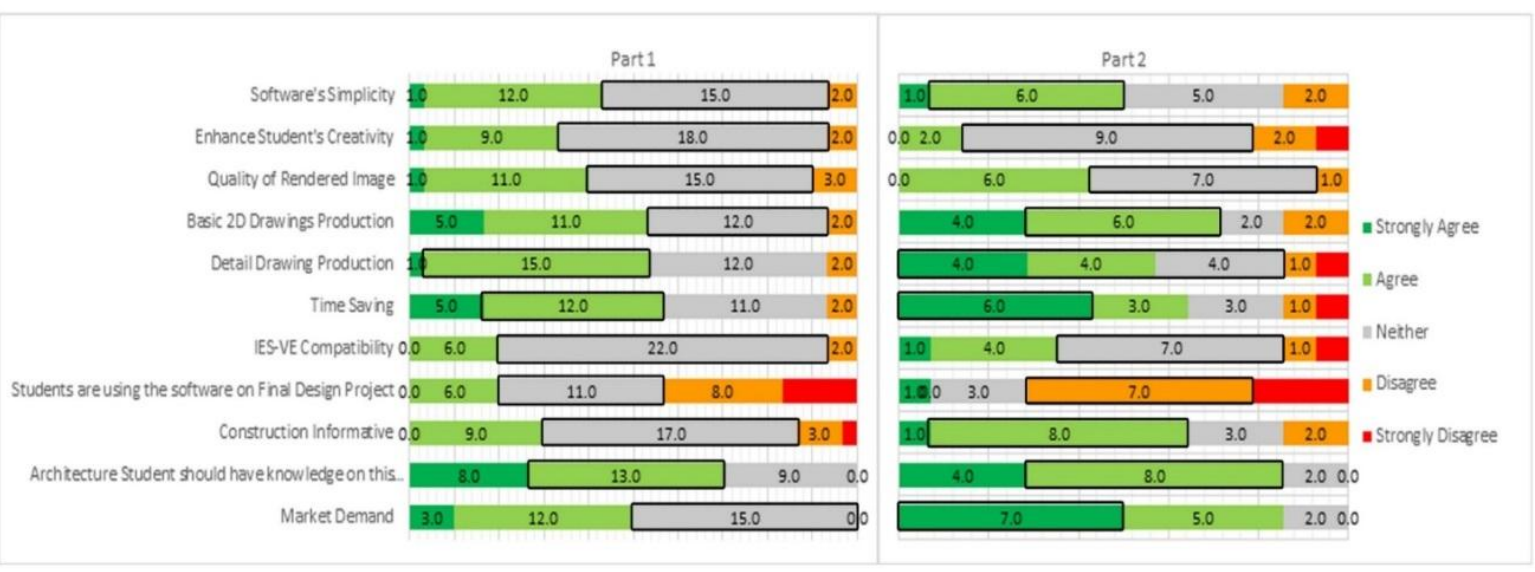

Figure 6.2 : Students' perception on Revit Software

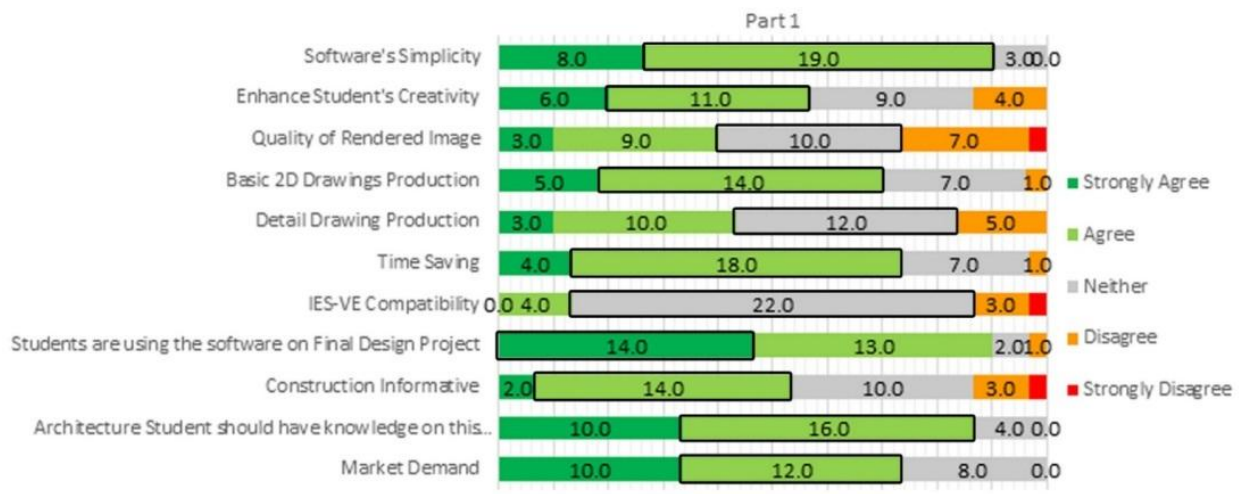

Figure 7.0: Part 1 students' perceptions on SketchUp software

Similar with the perception on Revit software, the perception result of the Part 2 students on SketchUp software were more diverse compared to their Part 1 counterpart (Figure 7.1). They strongly agreed (dark green colour) or agreed (light green colour) with 8 out of the 11 statements in the survey with regards to SketchUp.

To summarize, majority of the Part 2 students agreed on:

- The software's simplicity

- The software's ability to enhance the student's creativity

- The image rendering quality

- The software could save time (strongly agree)

- Data compatibility between IES-VE (building performance analysis software) and SketchUp

- Architecture students should have knowledge on this particular software (strongly agree)

- The use of the software by the students in the design studio project (strongly agree)
- Market demand for this software (strongly agree)

However, the students were uncertain (grey colour) on the statements:

- Is able to ease with the production of 2D drawings

- Its ability to give constructional information

- Detail drawings production

The result basically showed that Part 2 students were more aware of the capability of SketchUp software compared to their Part 1 counterparts. One example of this was that the Part 2 students knew that SketchUp software was not appropriate software to be used to produce basic 2D and detail drawings. Although SketchUp was an easy-to-use software, this software is not the appropriate tools in producing the $2 \mathrm{D}$ and detail drawings or commonly known as CAD drawings. SketchUp would normally be used to produce the 3D visualization or the conceptual 3D 
modelling for a project (Mohd-Nor \& Grant, 2014). This contradiction was possibly due to that the Part 2 students had a much longer experience dealing with SketchUp software in their architectural studio class and in their working period in architectural companies as compared to their Part 1 counterparts. Figure 7.2 shows both Part 1 and Part 2 perception on SketchUp results had been put side by side as a comparison.

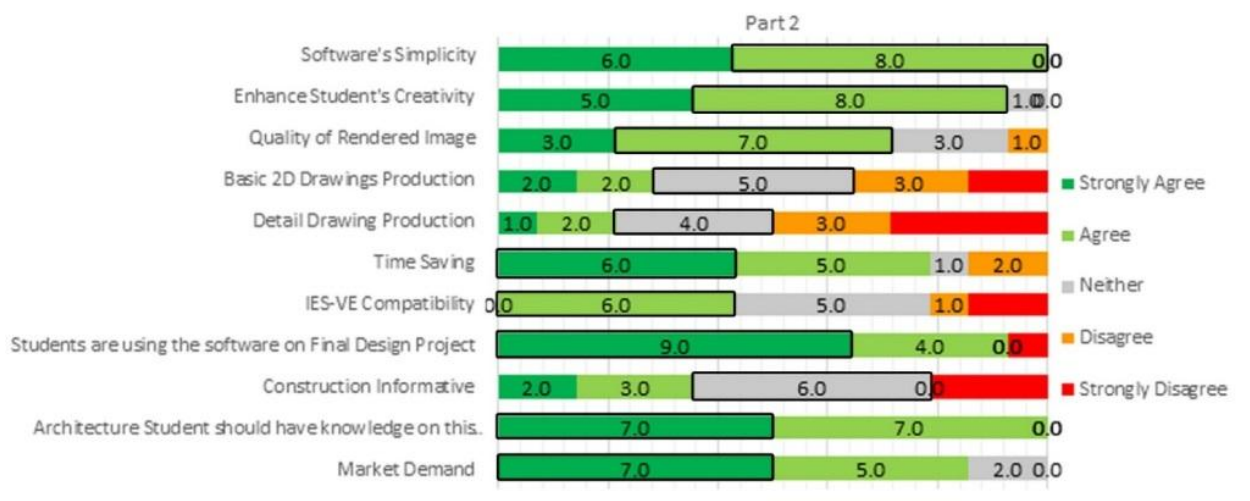

Figure 7.1: Part 2 students' perceptions on SketchUp software

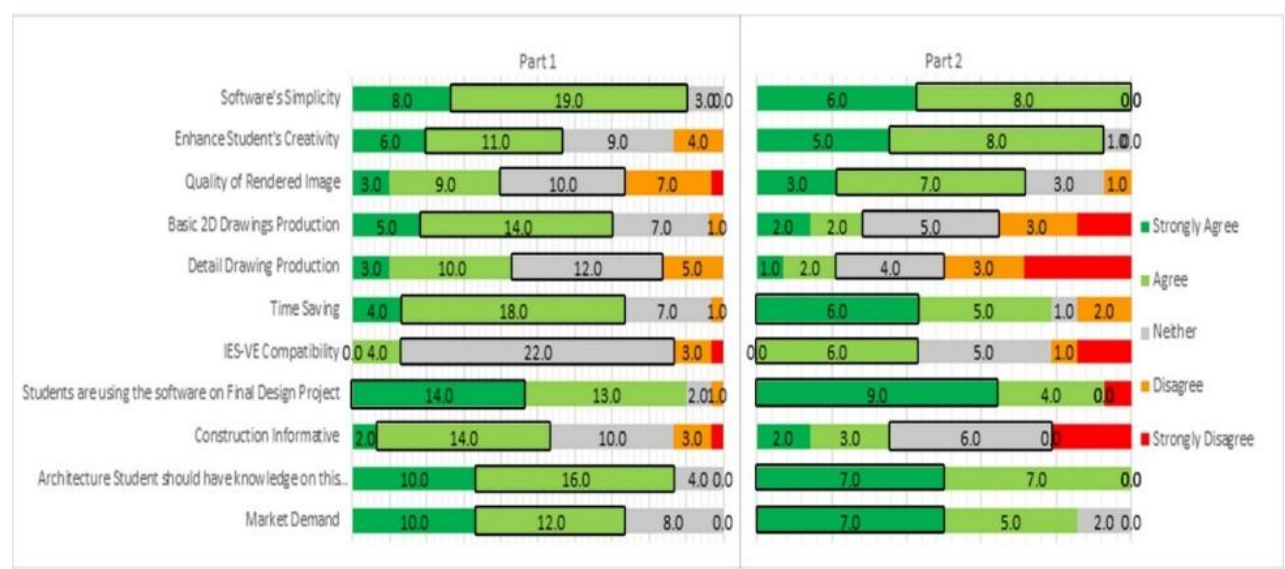

Figure 7.2: Students' perceptions on SketchUp software

\subsection{CONCLUSION}

From this study, the survey shows that the selected architecture students from Part 1 and 2 in UM for this study generally appreciate computer aided design software. AutoCAD - a 2D line based draughting software, is the most commonly used software in both education and practice. BIM software - Autodesk Revit, on the other hand, is not yet getting the momentum it should have although $80 \%$ of Malaysian architectural companies are reported to be aware of BIM (Mohd-Nor, 2014) and CIDB are heavily promoting the technology in Malaysia's construction industry (CIDB Malaysia, 2014).

The perception survey result shows that the selected architecture students have their own favourite design software to be used, mainly the one that is easy-to-use and that have more simple interface for them to create a more creative and innovative form for their building - namely SketchUp. Majority - if not all, of architecture students in this study are using this software for their architectural design studio project and in their previous work practice.

On the other hand, the result also shows that the students do have a positive outlook on Revit software - BIM software, although they never had any particular training or courses on the software. This gives an indication that they do have interest and probably have heard of the benefits and advantages on learning this particular BIM software. This gives an indication that an integration of the software into the curriculum or the software been taught as a subject would receive a positive participation from the students. 
This will then enable an introduction of BIM into the architecture education. Furthermore, this can also add more value to the students by acquiring the knowledge of the latest computer technology aswellasitwould also support the government'songoing BIM implementation plan.

\subsection{LIMITATION AND FUTURE RESEARCH}

The finding of this study would provide any interested researcher, designer or academics with fundamental understanding of students' perception and preference - particularly in the case of University of Malaya's architectural education before embarking on future studies on BIM. Listed below are the limitation and suggestion for future study and research:

- $\quad$ The result of this study would increase its reliability through expanding the population of the survey to other universities in Malaysia. These would help to further validate the results and to gain in-depth understanding into emerging issues and challenges discussed in this study.

- $\quad$ Since this study only examines BIM from the student's perspective - a bottom up perspective - it is strongly suggested that further studies that investigate BIM from experts' domain - the top down perspective - in architectural education, through interviews or focus group study with relevant industry practitioners to be done.

- $\quad$ One of the limitations of this study is that it only focuses on the application of BIM software amongst architecture students. According to the National Building Specification (NATSPEC) Australia 2013 report on BIM education, globally, majority of the available BIM education mainly focuses on training the usage of particular BIM software packages rather than training and collaborating in actual live project environments. Training and working in collaborative BIM environments, appears to still be in its infancy (NATSPEC Australia, 2014). Therefore, a viable research on this collaborative aspect of BIM would be required for future research to further expand the BIM education investigation.

\section{ACKNOWLEDGEMENT}

The authors would like to acknowledge the University of Malaya for the financial support to this paper. This work was supported by HIR Grant No: UM.C/HIR/MOHE/Arts/ and IPPP Grant No: UMRG-RP009E-13SUS.

\section{REFERENCES}

AUGI - Autodesk User Group International. (2009, March 11). Thread: Origin of the name Revit. Retrieved from AUGI Forum:

http://forums.augi.com/showthread.php? 109895-Origin-of-the-name-Revit

AUGI - Autodesk User Group International. (2013, June 11). Thread: Origins of Revit. Retrieved from AUGI Forum: http://forums.augi.com/showthread.php? 10925-Origins-ofRevit\&highlight=revit\%20history

Bergin, M. S. (2012, December 7). A Brief History of BIM . Retrieved from ArchDaily: ArchitectureNews:

http://www.archdaily.com/302490/a-brief-historyof-bim/

CIDB Malaysia. (2014). Building Information Modelling (BIM) Roadmap for Malaysia's Construction Industry Workshop Report Series 2. Kuala Lumpur: Construction Industry Development Board (CIDB) Malaysia.

CIDB Malaysia. (2015). Malaysia's Construction Industry Transformation Programme 2016-2020 : Driving Construction Excellence Together. Kuala Lumpur: Construction Industry Development Board (CIDB) Malaysia.

CREAM. (2014). Issues and Challenges in Implementing Building Information Modelling (BIM) for SME's in The Construction Industry. Kuala Lumpur: Construction Research Institute of Malaysia (CREAM).

Eastman, C., Teicholz, P., Sacks, R., \& Liston, K. (2011). BIM Handbook: A Guide to Building Information Modeling for Owners, Managers, Designers, Engineers, and Contractors - 2nd Edition. New Jersey: John Wiley \& Sons.

Haron, A. T. (2013, July). Organisational Readiness to Implement Building 
Information Modelling: A Framework for Design Consultants in Malaysia. University of Salford Manchester, Salford, UK.

Haron, A. T., Marshall-Ponting, A. J., Abd Hamid, Z., Mohamad Kamar, K. A., Abd Wahab, N., \& Abd Hamid, Z. (2012, August 20). Building Information Modelling (BIM): The Core Concept and the Benefits. Retrieved from INDUSTRIALISED BUILDING SYSTEM (IBS) RESEARCH AND INFORMATION: Offsite Construction Towards Mechanisation, Automation and Robotics:

http://ibsresearch.blogspot.com/2012/08/ building-information-modelling-bimcore.html

Kiker, M. W. (2009, June 23). More BIM Manager 2009 Survey Results. Retrieved from BIM Manager: http://www.bimmanager.com/2009/06/23 /more-bim-manager-2009-survey-results/

Klettner, A. (2013, March 5). bdonline.co.uk. Retrieved from Almost half of architects using http://www.bdonline.co.uk/almost-halfof-architects-using-bim/5051240.article

Levy, F. (2012). BIM in Small-Scale Sustainable Design. Hoboken, New Jersey: John Wiley \& Sons.

Lu, J. (2009). Effects of Traditional and DIgital Media on Student Learning in Space Design. The Scholarship of Teaching and Learning at EMU, 2(1), 5.

Mohd-Nor, M., \& Grant, M. P. (2014). The Development of Digital Architecture Modeling in the Malaysian Architecture Industry. RECENT ADVANCES in COMPUTER ENGINEERING, COMMUNICATIONS and INFORMATION TECHNOLOGY (pp. 77 - 84). Tenerife, Spain: WSEAS Press.
Mohd-Nor, M., Usman, I., \& Mazlan-Tahir, M. (2009). How the professional practice and the architecture education in Malaysia is catching up with the development of CAD . European Journal of Social Sciences, Pages 677-683.

NATSPEC Australia. (2014). BIM Education Global Summary Report 2013. Sydney: NATSPEC Australia.

Pittard, S. (2012). What is BIM? Retrieved from http://fat.glam.ac.uk/media/files/docume nts/2012-03-16/What_is_BIM_1_.PDF

Renaud Vanlande, C. N. (2008). IFC and Buildings Lifecycle Management. Automation in Construction, 70-78.

Succar, B. (2009). Building information modelling framework: A research and delivery foundation for industry stakeholders. Automation in Construction 18 (2009), 357-375.

Taylor, J. (2009, August 28). Computers \& IT: SIMPLICITY WITH AUTODESK® REVIT ARCHITECTURE®. Retrieved from Simply Links: http://www.simplylinks.co.za/article407_ simplicitywithautodeskrevitarchitecture.h tm

Teer, M. (2014, June 27). Black Spectacles. Retrieved from REQUIREMENTS TO $\begin{array}{llll}\text { WORK IN THE TOP } 50 & \end{array}$ ARCHITECTURE FIRMS: http://blackspectacles.com/blog/softwarelicensure-requirements-to-work-top-50architecture-firms\#.U8RJzI1dWkT

Waterhouse, R. (2013). National BIM Report 2013. London, UK: RIBA Enterprise Ltd.

Zahrizan Zakaria, N. M.-P. (2013). IJRET: International Journal of Research in Engineering and Technology, 384 - 395. 